\title{
PENGEMBANGAN SISTEM INFORMASI MANAJEMEN PRAKTIK INDUSTRI DI JURUSAN PENDIDIKAN TEKNIK ELKTRONIKA UNY BERBASIS WEBSITE MENGGUNAKAN YII FRAMEWORK
}

\author{
Agung Rizki Subhan \& Handaru Jati \\ Universitas Negeri Yogyakarta \\ e-mail: agungsubhan@gmail.com
}

\begin{abstract}
The research aims to develop an Internship Management Information System at Electronics Engineering Education Departmentt of Yogyakarta State University. The development was conducted on July, 2016 until December, 2016 at Electronics Engineering Education Department of Yogyakarta State University. Development is done by using the waterfall model. The waterfall model consists of system requirements analysis, system design, system implementation and system testing. The result of this research is Web-Base Internship Management Information System Software at Electronics' Engineering Education Department of Yogyakarta State University using Yii Framework. The functionality of the system was tested by 3 testers which each tested 52 functions. From these tests, all functions that have been tested can run well. Thus, the produced software has been meets the need to manage the implementation of industry practices.
\end{abstract}

Keywords: information system, website, internship, yii framework

\begin{abstract}
ABSTRAK
Penelitian ini bertujuan untuk mengembangkan Sistem Informasi Manajemen Praktik Industri di Jurusan Pendidikan Teknik Elektronika Universitas Negeri Yogyakarta. Pengembangan dilakukan pada Juli 2016 sampai Desember 2016 di Jurusan Pendidikan Teknik Elektronika UNY. Pengembangan dilakukan dengan menggunakan model waterfall. Model waterfall terdiri dari analisis kebutuhan sistem, desain sistem, implementasi sistem dan pengujian sistem. Hasil dari penelitian ini adalah software Sistem Informasi Manajemen Praktik Industri di Jurusan Pendidikan Teknik Elektronika UNY berbasis web menggunakan Yii Framework. Fungsionalitas sistem diuji oleh 3 orang penguji yang masing masing menguji 52 fungsi. Dari pengujian tersebut, semua fungsi yang telah diuji dapat berjalan dengan baik. Sehingga, software yang dihasilkan telah memenuhi kebutuhan untuk mengelola pelaksanaan praktik industri.
\end{abstract}

Kata kunci: sistem informasi, website, praktik industri, yii framework

\section{PENDAHULUAN}

Universitas Negeri Yogyakarta (UNY) sebagai salah satu dari institusi pendidikan selalu berusaha untuk menghasilkan lulusan yang berkualitas. Berbagai upaya dilakukan untuk dapat menghasilkan lulusan yang siap memenuhi kebutuhan dunia kerja. Salah satu upaya yang dilakukan UNY adalah membekali mahasiswa kompetensi teknis berdasarkan pengalaman nyata. Sejalan dengan upaya tersebut, Fakultas Teknik Universitas Negeri Yogyakarta ( FT UNY ) memasukan
Matakuliah Praktik Industri kedalam mata kuliah yang wajib ditempuh mahasiswa.

Menurut Pendoman Praktik Industri FT UNY (Tim PI, 2016:2), Program Praktik Industri khususnya di FT UNY menjadi salah satu matakuliah wajib dengan bobot kredit 3 SKS. Pelaksanaannya minimal selama 2 bulan dan 256 jam dengan sistem blok pada semester gasal, semester genap maupun semester khusus.

Tata cara pelaksanaan praktik industri diatur dalam pedoman praktik industri yang berupa buku cetak atau file Portable Document 
Format (PDF) yang dapat diunduh melalu situs FT UNY. Pedoman tersebut memberikan gambaran tentang tata cara pelaksanaan praktik industri. Namun, pedoman tersebut kurang memberikan informasi terkini tentang pelaksanaan praktik industri.

Agar praktik industri dapat berjalan dengan baik dan tepat sasaran tentunya kegiatan ini harus diorganisasi dengan baik. Dengan model pengelolaan yang ada saat ini, Koordinator Praktik Industri mengalami beberapa kesulitan dalam mengelola pelaksanaan praktik industri. Salah satu kesulitan yang ada adalah pengelolaan proposal praktik industri yang masuk.

Koordinator praktik industri juga membutuhkan beberapa informasi sebagai acuan untuk menentukan dosen pembimbing. Beberapa informasi yang dibutuhkan antara lain, beban bimbingan yang telah dimiliki dosen, keahlian praktik industri yang dipilih peserta atau wilayah pelaksanaan praktik industri. Kurangnya akses yang cepat dan akurat terhadap informasi tersebut tentunya menjadi kendala bagi koordinator untuk menentukan dosen pembimibing bagi peserta.

Dalam memilih dan menetapkan Mitra Industri, terdapat pedoman keahlian bagi peserta yang disesuaikan dengan program studi yang diambil. Terbatasnya media penyebaran informasi tempat praktik industri yang relevan terhadap keahlian program studi peserta menjadi kendala bagi peserta untuk menentukan tempat praktik industri. Kemudian, akses informasi tentang lokasi praktik industri yang sedang diambil peserta praktik informasi yang kurang cepat dan akurat juga menjadi kendala bagi koordinator maupun dosen pembimbing untuk memantau pelaksanaan praktik industri.

Saat melaksanakan praktik industri, peserta harus menyerahkan jadwal kegiatan dan berkonsultasi dengan dosen pembimbing secara rutin. Untuk menentukan waktu bimbingan dengan dosen pembimbing tentu bukan perkara mudah. Beberapa kendala bimbingan yang ada antara lain waktu, lokasi praktik industri, serta media bimbingan yang kurang memadai.

Pada akhir pelaksanaan praktik industri, peserta wajib membuat laporan pelaksanaan praktik industri dan melaksanakan ujian praktik industri. Menurut pedoman praktik industri (Tim PI, 2016:7) laporan dan ujian praktik industri harus dilaksanakan paling lambat satu bulan setelah praktik industri selesai. Bila peserta tidak menyelesaikan hingga batas waktu yang ditentukan, pelaksanaan praktik industri harus diulang kembali.

Setelah laporan, ujian dan revisi diselesaikan, dosen pembimbing memberikan penilaian terhadap pelaksanaan praktik industri peserta yang mengacu pada penilaian industri terhadap peserta dan hasil laporan praktik industri. Penilaian dari dosen pembimbing terhadap peserta masih melalui beberapa proses manual dan belum bisa secara langsung diberikan dosen melalui sistem yang ada sehingga proses penilaiannya memakan waktu yang lebih lama. Berdasarkan latar belakang tersebut, diperlukan adanya sistem informasi yang membantu pengelolaan kegiatan praktik industri.

\section{METODE}

Pendekatan yang digunakan dalam penelitian ini adalah pendekatan penelitian pengembangan atau R\&D (Research and Development). Model pengembangan yang digunakan dalam penelitian ini adalah model waterfall. Model waterfall memiliki urutan pengembangan yang dimulai dari analisis kebutuhan, desain, implementasi kemudian pengujian (Bassil, 2012:743). Model waterfall dipilih karena memiliki tahapan pengembangan yang jelas, dan setiap tahapan yang ada dijalankan setelah tahapan sebelumnya selesai dijalankan sehingga tidak terdapat tumpang tindih pada setiap tahapannya.

Pada penelitian pengembangan ini, letak penelitian terdapat pada pengujian 
perangkat lunak yang dihasilkan dan pengembangannya terletak pada analisis kebutuhan, desain dan implementasi. Dengan demikian, diharapkan penelitian pengembangan ini menghasilkan produk yang siap digunakan secara nyata dan memenuhi kebutuhan pengguna. Berikut ini prosedur pengembangan perangkat lunak dengan model waterfall.

Analisis kebutuhan dilakukan untuk mengetahui segala informasi mengenai manajemen praktik industri di Jurusan Pendidikan Teknik Elektronika Fakultas Teknik Universitas Negeri Yogyakarta (PTE FT UNY). Untuk mengumpulkan informasi tersebut, peneliti menggunakan metode wawancara dan observasi.

Desain sistem merupakan tahap dimana hasil dari analisis kebutuhan diterjemahkan menjadi model atau bentuk yang mengambarkan sistem yang akan dibuat. Pada penelitian ini, perancangan sistem digambarkan dalam bentuk Unified Modeling Language (UML). UML yang digunakan dalam mendesain sistem ini antara lain Use Case Diagram, Class Diagram, Sequence Diagram dan Activity Diagram. Selain perancangan menggunakan UML, terdapat perancangan antarmuka dan perancangan basis data untuk sistem yang akan dikembangkan.

Pada tahap implementasi, desain sistem yang telah dirancang diterapkan menjadi kode program sehingga menghasilkan perangkat lunak yang memiliki fungsi sesuai yang diinginkan. Untuk memudahkan dan menjaga kualitas perangkat lunak pengembangan ini menggunakan Yii Framework. Yii Framework membantu agar perangkat lunak berbasis web dapat dikembangkan dengan cepat dan aman. Yii Framework digunakan untuk membantu menangani pemrograman sistem yang meliputi kontroler, tampilan dan koneksi basis data. Sedangkan basis data akan diimplementasikan dengan menggunakan PostgreSQL.

Pengujian adalah proses mencari kesalahan yang mungkin terjadi dalam pengembangan perangkat lunak. Tahap ini dilakukan untuk menguji apakah perangkat lunak dapat digunakan dan berfungsi dengan baik. Pengujian perangkat lunak dilakukan dengan instrumen berdasarkan standar ISO 9126 sehingga dapat dilakukan evaluasi sebelum akhirnya perangkat lunak digunakan oleh pengguna.

\section{HASIL}

Sistem dirancang untuk mengatasi permasalahan pelaksanaan praktik industri di Jurusan Pendidikan Teknik Elektronik UNY. Sasaran pengguna dari sistem ini adalah admin, koordinator, dosen pembimbing, dan mahasiswa peserta.

Fungsionalitas yang dimiliki masingmasing pengguna antara lain: (1) Admin dapat mengelola data jurusan dan program studi yang menyelenggarakan Praktik Industri beserta fungsi untuk mengangkat koordinator masing-masing jurusan; (2) Koordinator praktik industri dapat mengelola data peserta praktik industri seperti melihat data peserta praktik industri, menerima proposal praktik industri menentukan dosen pembimbing bagi peserta praktik industri, menerima laporan pelaksanaan praktik industri, mengelola pengumuman pelaksanaan praktik industri; (3) Dosen pembimbing dapat mengelola data peserta praktik industri yang dibimbing seperti melihat data peserta, menerima proposal, menerima laporan, memberi penilaian serta mengirim atau menerima pesan bimbingan dari mahasiswa praktik industri yang dibimbing; (4) Mahasiswa praktik industri dapat mengirimkan proposal praktik industri, mengirim atau menerima pesan bimbingan dari dosen pembimbing, mengirim laporan praktik industri serta melihat pengumuman praktik industri.

Sistem dikembangkan pada platform web yang dapat diakses menggunakan web browser. Sistem dibangun dengan PHP menggunakan kerangka kerja Yii yang 
didukung dengan JavaScript, CSS serta HTML 5. Basis data yang digunakan adalah PostgreSQL. Sistem menggunakan web service untuk berkomunikasi dengan sistem yang telah dimiliki UNY untuk memperoleh informasi dosen dan mahasiswa.
Desain sistem yang dikembangkan meliputi perancangan Unified Modelling Language (UML), basis data dan tampilan. Desain fungsionalitas sistem digambarkan menggunakan use case diagram. Use case diagram untuk aktor admin dapat dilihat pada Gambar 1.

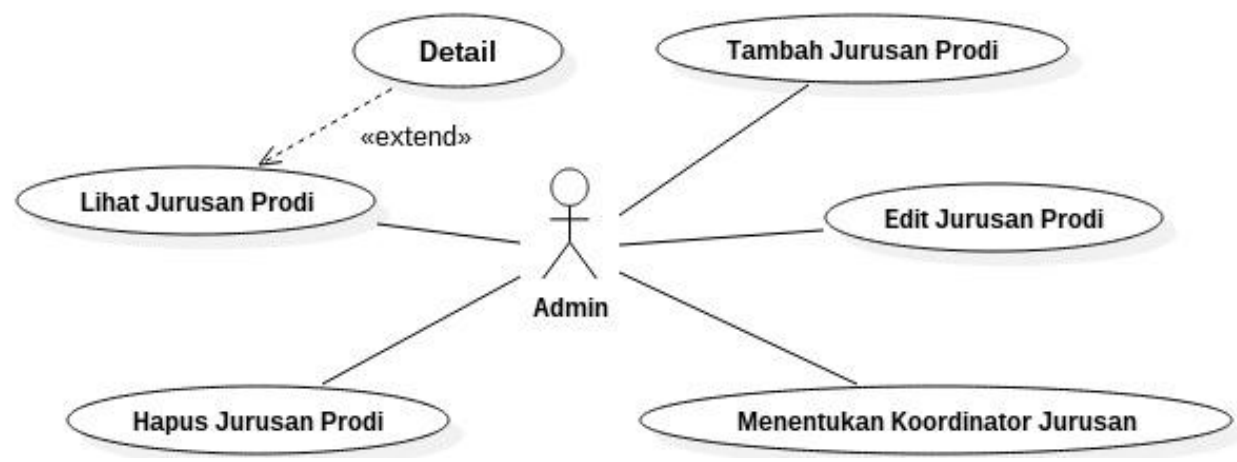

Gambar 1. Use Case Diagram Admin

Desain diagram use case untuk koordinator dapat dilihat pada Gambar 2 berikut ini.

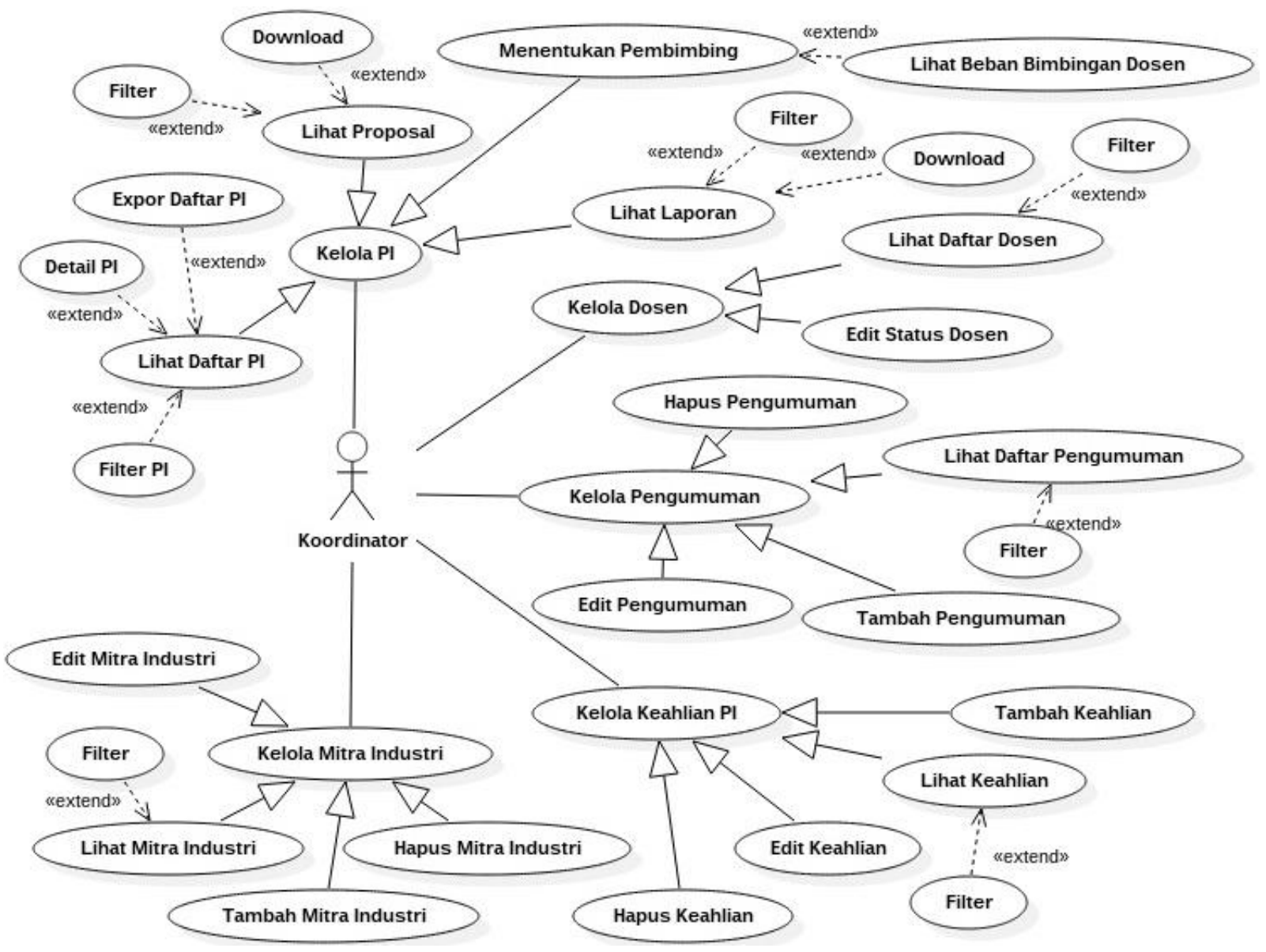

Gambar 2. Use Case Diagram Koordinator 
Desain diagram use case untuk dosen

berikut ini.

pembimbing dapat dilihat pada Gambar 3

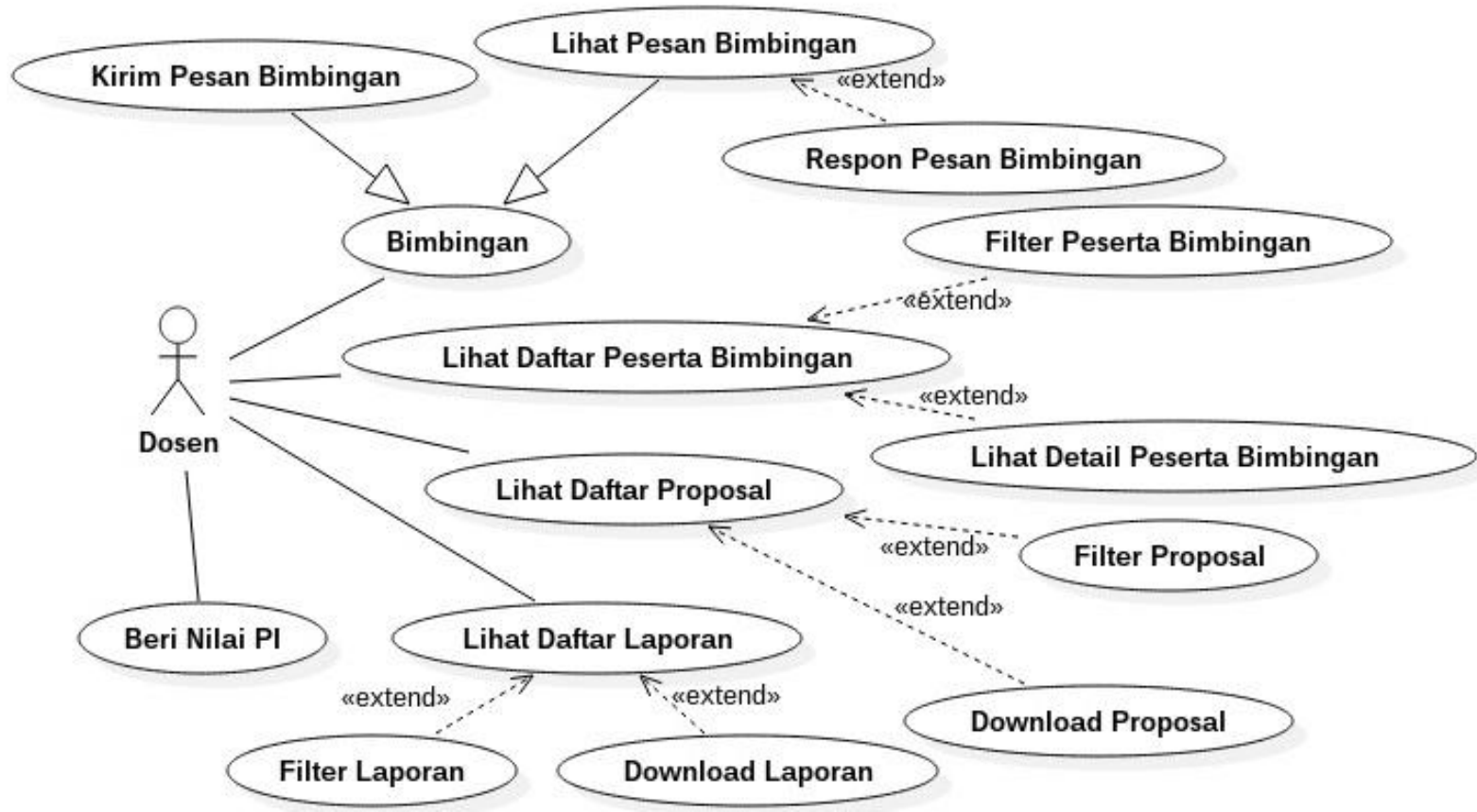

Gambar 3. Use Case Diagram Dosen Pembimbing

Desain diagram use case untuk

dilihat pada Gambar 4 berikut ini.

mahasiswa peserta praktik industri dapat

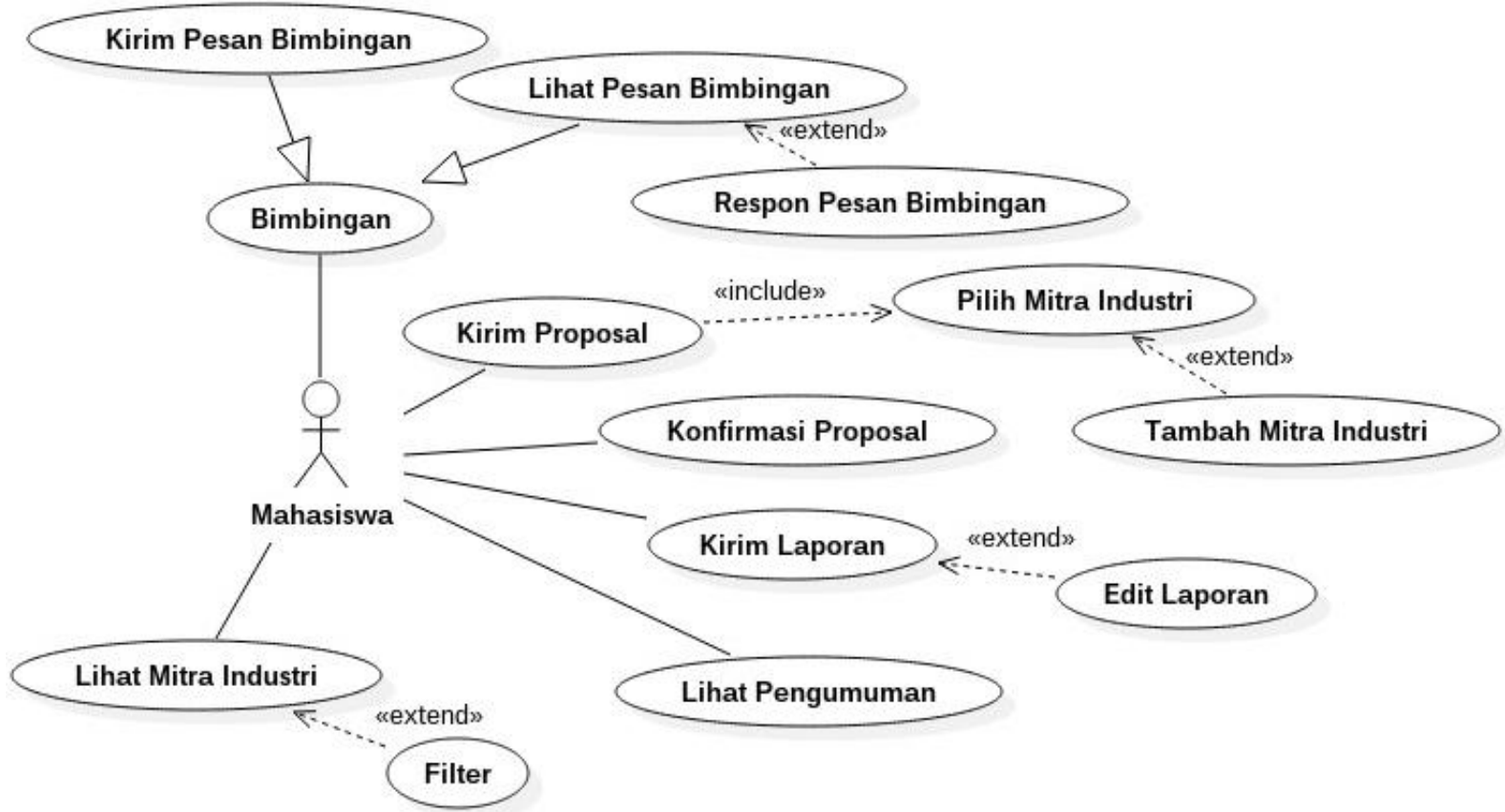

Gambar 4. Use Case Diagram Mahasiswa 
Desain basis data untuk sistem Gambar 5 berikut : informasi praktik industri ditunjukkan dalam

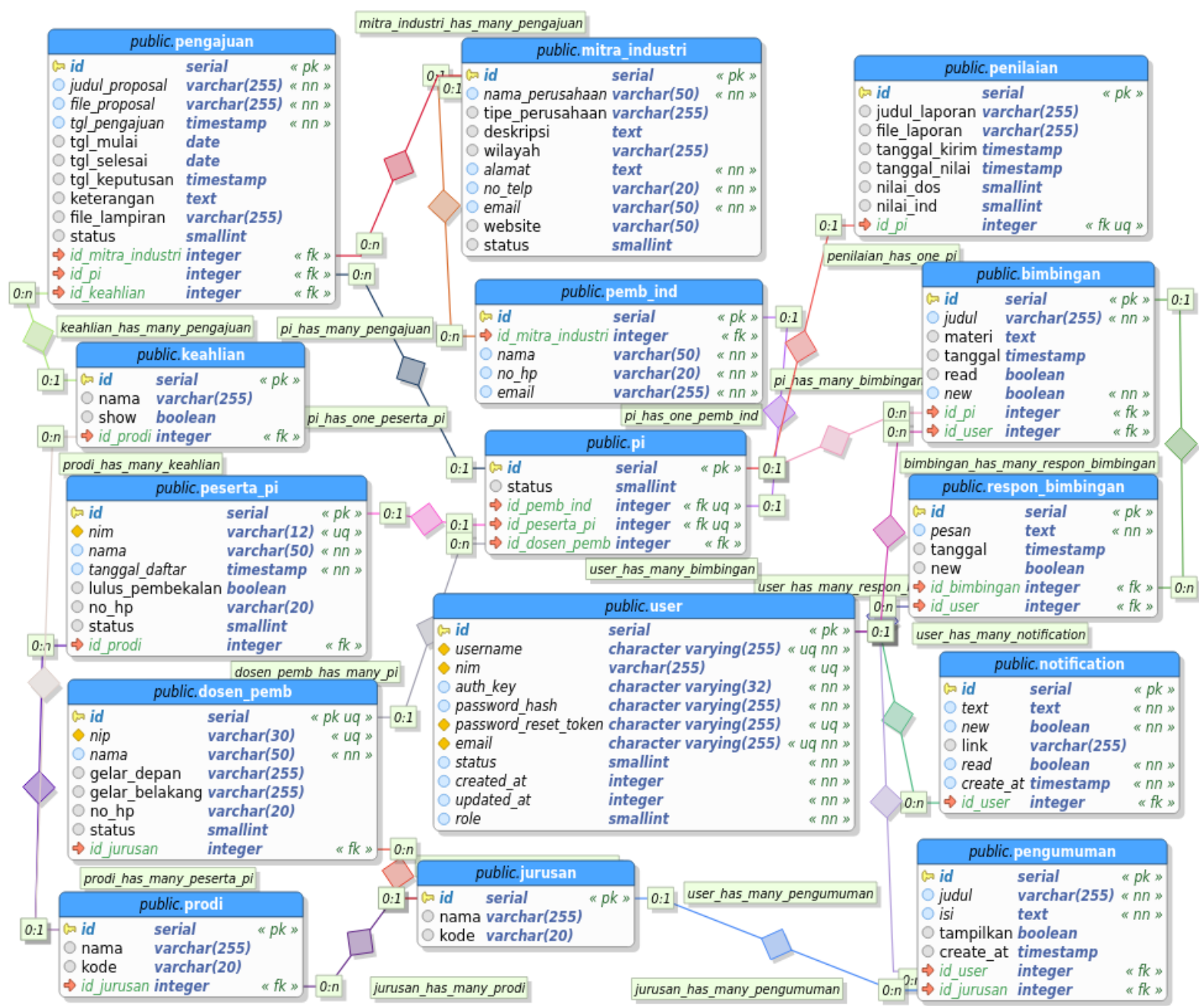

Gambar 5. Desain Basis Data

Desain tampilan (user interface) halaman utama untuk mahasiswa Sistem
Informasi Manajemen Praktik industri dapat dilihat pada Gambar 6 berikut ini. 


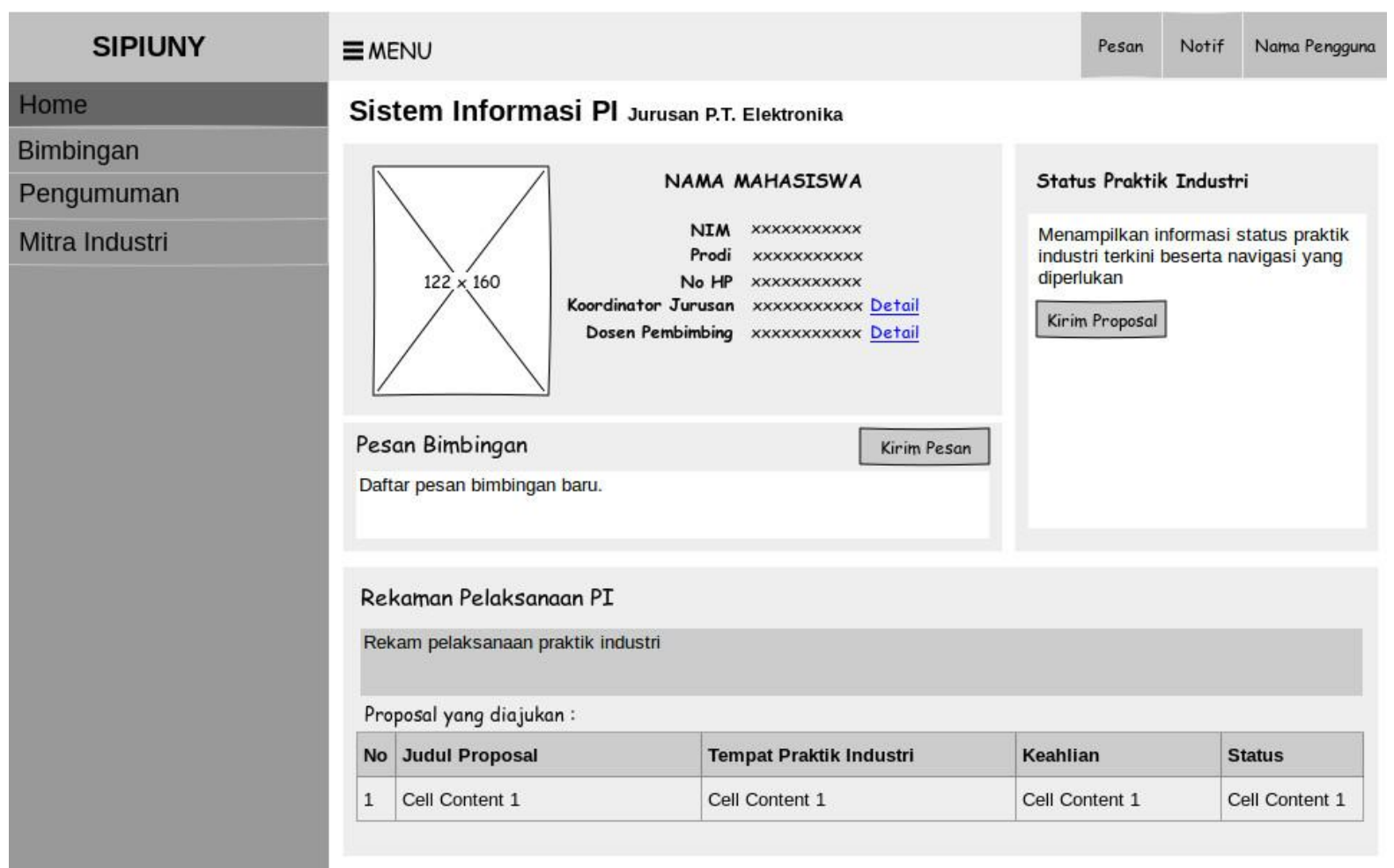

Gambar 6. Desain User Interface Dashboard Mahasiswa

Desain tampilan (user interface) dapat dilihat pada Gambar 7 berikut ini. halaman bimbingan mahasiswa dan dosen

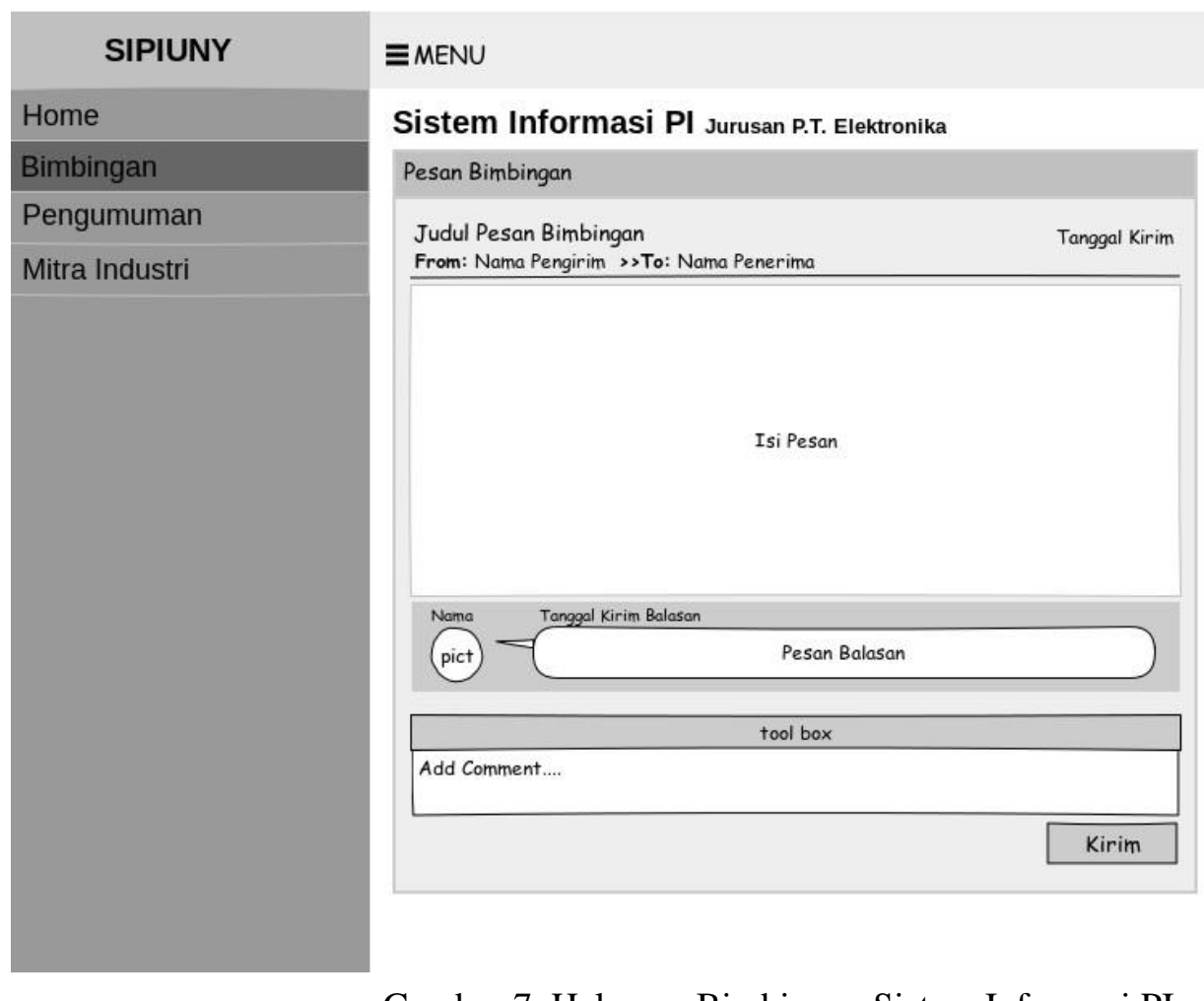

Pesan Notif Nama Pengguno

Gambar 7. Halaman Bimbingan Sistem Informasi PI 
Implementasi dilakukan dengan menggunakan framework Yii 2.0 untuk membangun sistem dengan fungsionalitas yang dibutuhkan. Framework Yii 2.0 menggunakan pola Model-View-Controller (MVC). Basis data diimplementasikan kedalam PostgreSQL dan antar muka diimplementasikan dengan menggunakan kode HTML, CSS dan JavaScript.

Basis data untuk sistem informasi manajemen praktik industri diimplementasikan dalam PostgreSQL yang dapat dilihat dalam Gambar 8 berikut ini. Data dalam sistem disimpan dalam 15 tabel yang saling berelasi satu sama lain.

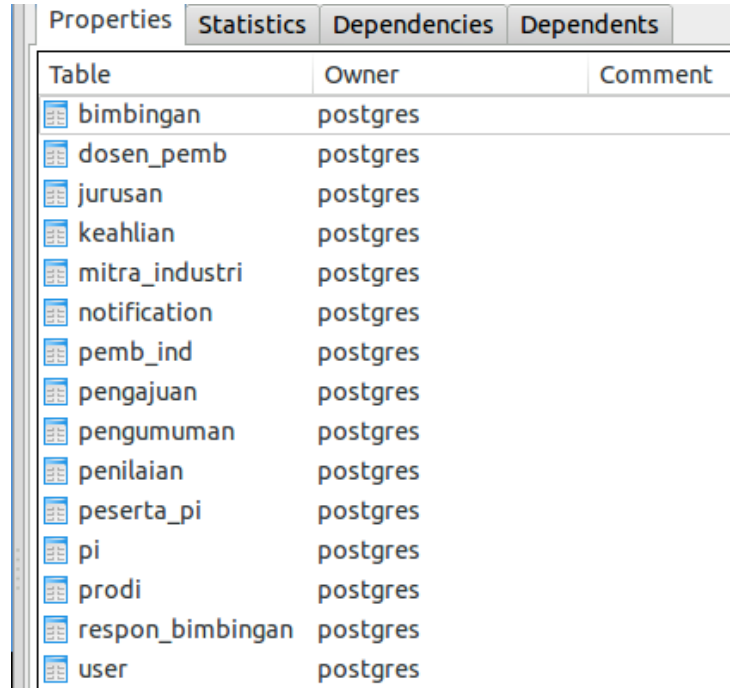

Gambar 8. Implementasi Basis Data

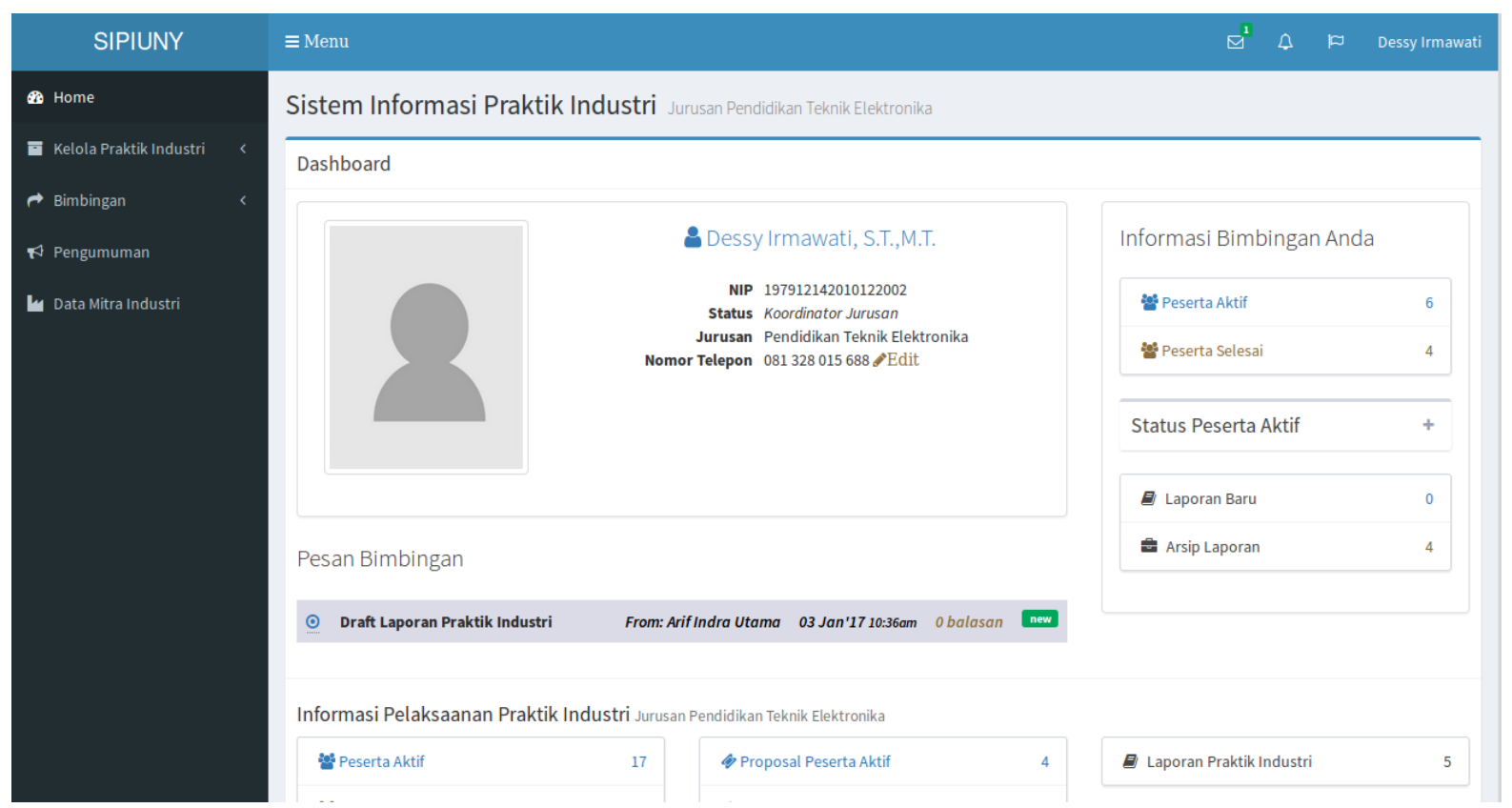

Gambar 9. Implementasi Halaman Utama Koordinator PI

Implementasi halaman utama untuk koordinator jurusan pada sistem informasi praktik industri seperti pada Gambar 9. Dalam halaman tersebut terdapat data Koordinator PI (Dashboard), Pesan Bimbingan, Informasi Pelaksanaan PI, Informasi Bimbingan, status Peserta Aktif dan sebagainya.
Implementasi halaman pesan bimbingan pada sistem informasi praktik industri seperti pada Gambar 10. 


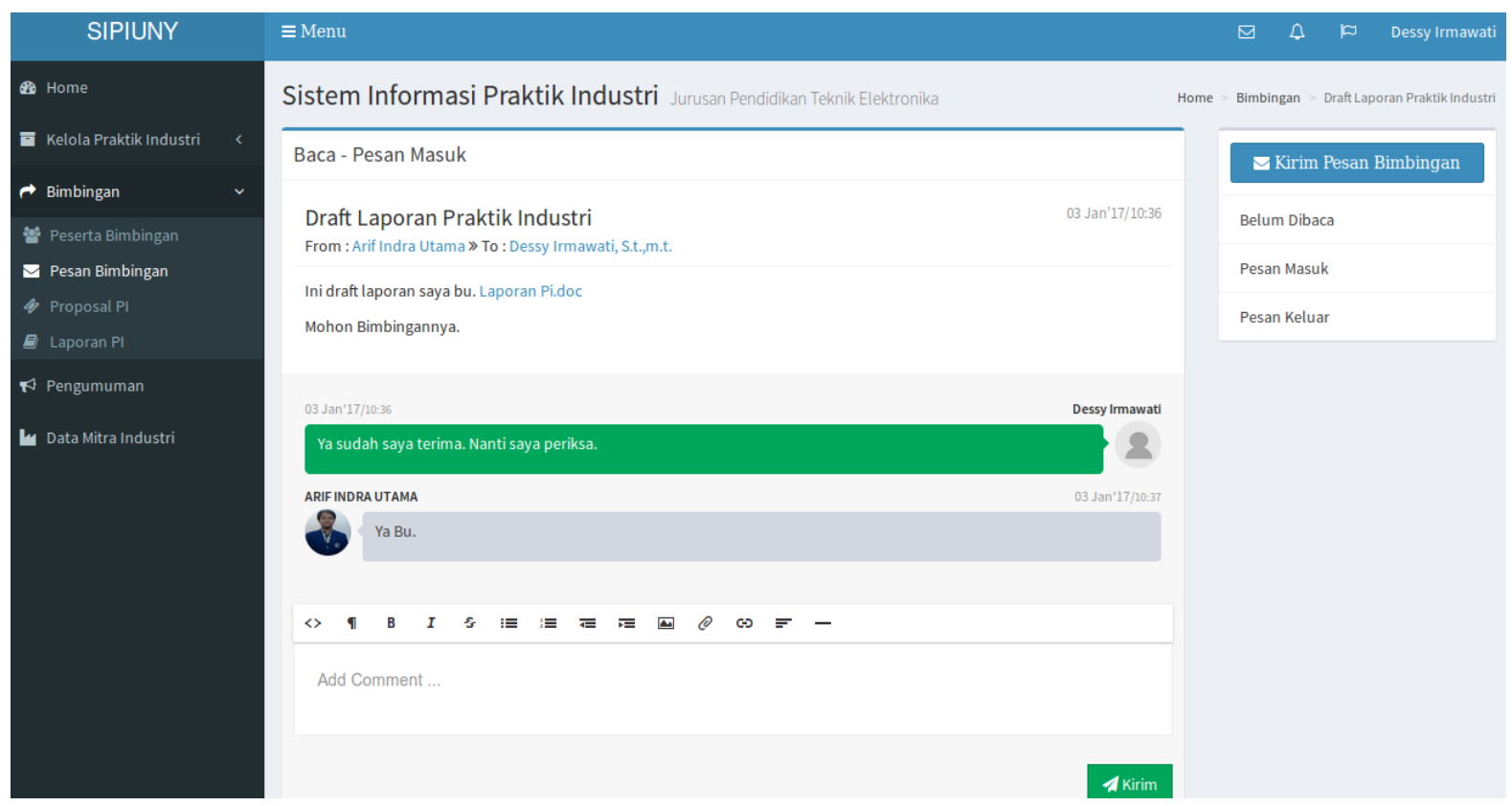

Gambar 10. Implementasi Halaman Bimbingan Sistem PI

Pengujian dilakukan dengan cara menguji setiap fungsi ada dalam sistem. Sistem memiliki 62 fungsi sesuai kebutuhan pengguna berdasarkan hasil analisis kebutuhan sistem. Pengujian dilakukan oleh tiga orang ahli pemrograman. Berdasarkan hasil pengujian, semua fungsi yang ada dalam sistem telah dapat berjalan dengan baik.

\section{SIMPULAN}

Berdasarkan hasil penelitian dan pembahasan yang dilakukan, dapat disimpulkan bahwa Penelitian ini menghasilkan sistem informasi praktik industri Jurusan Pendidikan Teknik Elektronika UNY berbasis web menggunakan Yii Framework. Fungsionalitas sistem diuji oleh 3 orang penguji yang masing masing menguji 52 fungsi. Sistem yang dihasilkan telah dapat memenuhi kebutuhan pengguna yang terdiri dari mahasiswa, dosen pembimbing dan koordinator praktik industri. Fungsi sistem secara umum antara lain manajemen praktik industri, manajemen bimbingan dan manajemen mitra industri. Dari pengujian tersebut, semua fungsi yang telah diuji dapat berjalan dengan baik. Oleh karena itu, software yang dihasilkan telah memenuhi kebutuhan untuk mengelola pelaksanaan praktik industri. Berdasarkan simpulan serta keterbatasan produk pada penelitian ini, peneliti memberikan saran untuk pengembangan yang akan datang sebagai berikut: (1) sistem diintegrasikan dengan sistem yang telah dimiliki UNY; (2) sistem informasi dikembangkan lebih lanjut pada platform mobile; (3) mengimplementasikan fitur yang belum ada; dan (4) teknik pengujian kualitas perangkat lunak lebih ditingkatkan dengan memperhatikan setiap sub karakteristik pada masing-masing karakteristik standar kualitas yang ada.

\section{DAFTAR PUSTAKA}

Bassil, Y. 2012. A simulation model for waterfall software development life cycle. International Journal of Engineering \& Technology (iJET). ISSN: 2049-3444, Vol. 2, No. 5

Tim Praktik Industri. 2016. Pedoman praktik industri. Yogyakarta: FT UNY 